Yuxtaposición consecutiva:

"Mucho crecen las nuevas de mio Çid el Campeador, bien casariemos con sus fijas pora huebos de pro". (Cid, 1373.1374).

A través de este trabajo he tratado de mostrar que el juglar no siempre ajusta todo lo que recita a la unidad métrica, es decir, al verso, sino que en muchas ocasiones agrupa dos versos. Al estudiar la relación que se establece entre los dos versos del dístico, hemos visto que los casos de encabalgamiento son muy pocos; como dice De Chasca: “. . . al presentar la canción re-creada en forma variada (nunca repetida de memoria sin variaciones), el juglar puede manejar versos cabales más fácilmente que versos encabalgados..."35. En los dísticos sin encabalgamiento, la relación más frecuente entre los dos versos es la yuxtaposición, y le siguen en orden la subordinación y la coordinación. En el caso de versos yuxtapuestos, muchas veces es difícil establecer qué tipo de yuxtaposición hay, porque la relación tiene varios matices. Sin embargo, la yuxtaposición cumple una función muy importante, ya que "esa soldadura, esa matización que ha de hacer el lector, le exige penetrar más profundamente en el signo expresivo, valorizarlo con más intensidad. [...] Sobre una frase (portentosa complejidad que hace pensar en técnica moderna) se montan -lo hemos visto- cuatro o cinco planos afectivos e intencionales" ${ }^{\prime \prime}$.

“...El estilo del Cantar - dice De Chasca- manifiesta una fuerte propensión a la disposición bimembre. [...] La unidad métrica en sí -un verso de dos hemistiquios - forma una base dual de la expresión que favorece la cristalización verbal de las ideas netamente contenidas dentro de dichas unidades' 37 . Por lo tanto, podemos considerar al dístico como un elemento más del dualismo que caracteriza al Poema.

El Colegio de México.

Laura Cázares

\title{
EL "CiANTO DEL CABALLERO" Y EL CABALLERO DE OLMEDO
}

En su reciente edición del Caballero de Olmedo de Lope, Joseph Pérez recuerda el acontecimiento de 1521 que dio origen a la leyenda y dice: "Pronto se borran las circunstancias del suceso; sólo queda el recuerdo del joven caballero muerto en el camino de Medina del Campo a Olmedo, y una copla canta su destino trágico:

Que de noche le mataron

al caballero,

la gala de Medina,

la flor de Olmedo,

35 DE Chasca, op. cit., p. 201.

36 Dámaso Alonso, op. cit., p. 77.

37 DE Chasca, loc. cit. 
copla que se hace rápidamente popular. A mediados del siglo, Antonio de Cabezón (1510-1566) compone unas melancólicas Diferencias sobre el canto llano del caballero [...] El hecho demuestra la difusión de la copla"1.

El editor recoge aquí una idea muy generalizada: que el "canto del caballero" que sirvió de base a la composición organística de Cabezón era la canción sobre el Caballero de Olmedo, o sea, la melodía de "Que de noche le mataron..." Como esta copla sólo está directamente documentada a partir de comienzos del siglo xvir, se ha visto en las Diferencias de Cabezón un precioso testimonio de su temprana creación y divulgación.

Quizás el primero en identificar las Diferencias con la copla fue Felipe Pedrell, que había publicado las obras de Cabezón y pudo comprobar la facilidad con que la letra de la estrofita se amolda a la melodía utilizada por el organista. En 1918 menciona Pedrell, "entre las obras de Cabezón [...], la que titula Canción del Caballero, inspirada, sin duda, en la tonada de aquel romance (sic) que empieza «Esta noche le mataron / al Caballero...."2. Pero la consagración definitiva de esta hipótesis se debió muy probablemente a don Jesús BaL, quien en sus Treinta canciones de Lope de Vega (1935) incluyó la partitura de Cabezón y comentó: "Esta melodía es la que seguramente se cantaba con los cuatro primeros versos - populares- de la letra que nos da Lope en su Caballero de Olmedo"3.

Gracias a esta seguridad de Jesús Bal, la identificación del "canto llano del Caballero" con el cantar sobre la muerte del Caballero de Olmedo se ha convertido en un tópico, repetido, sin asomo de duda, por editores y estudiosos de la tragicomedia lopesca. Blecua, por ejemplo, en su edición de 1947, se hace eco de los juicios de Bal, da por hecho que "el célebre músico Antonio de Cabezón le puso música" a la "canción del Caballero de Olmedo" y reproduce al final la partitura incluida en las Treinta canciones ${ }^{4}$. Era, en efecto, hermoso saber

1 LOPE DE VegA, El Caballero de Olmedo, ed. J. Pérez, Madrid, 1970 (Clásicos Castalia, 19), p. 8.

2 Cancionero musical popular español, Barcelona, [1918-1922], t. 1, 2a ed., p. I3. Pedrell había publicado la obra de Cabezón en su Hispaniae Schola Musica Sacra, Leipzig, 1894-1898, t. 3 (1895). Es de notar que en 1911 Cotarelo no menciona aún la música de Cabezón al hablar del baile del Caballero en la Introducción a su Colección de entremeses..., NBAE, t. 17, pp. ccxxxv s.; en cambio alude a la pieza de Pisador que menciono infra, nota 6.

3 Publicación de la revista Residencia, Madrid, 1935. En las pp. 59-62, la música de las "Diferencias sobre el canto llano del Caballero", seguida del texto que trae Lope; el comentario de Bal, pp. 106-107.

4 LOPE DE VeGA, El Caballero de Olmedo, Selección, estudio y notas de J. M. Blecua, Madrid, 1972 (Clásicos Ebro, 28), p. 23. Cf. también p. 20: "Se acentuaria todavía más esta nota de misterio si se oía al mismo tiempo, como tal vez sucediese, la melancólica copla cantada al son de las famosas diferencias del músico Cabezón". Francisco Rico (ed. de El Caballero de Olmedo, Salamanca, 1967, pp. 2526) sólo alude a la divulgación que "la canción del Caballero de Olmedo" tuvo en "toda España ya a mediados del siglo xvi". WArdropper afirma en 1970: "The song was well known; it had even been arranged as a set of variations by the composer Antonio de Cabezón" (Teatro español del Siglo de Oro, New York, 1970, p. 148). Cf. también E. Juliá Martínez, Observaciones preliminares a su ed. de la anónima Comedia del Caballero de Olmedo [ca. 1606], Madrid, 1944, p. 73 (cita 
que un compositor del siglo xvi había recogido de la tradición oral el cantarcito que tanto tiempo después daría pie a una de las más prodigiosas creaciones de Lope de Vega.

Lástima que no sea así. Ese caballero del canto armonizado por Antonio de Cabezón no er a el de Olmedo, sino un anónimo y genérico "caballero", objeto de una conocida canción de cuño tradicional:

$$
\begin{aligned}
& \text { Dezilde al cavallero } \\
& \text { que non se quexe, } \\
& \text { que yo le doy mi fe } \\
& \text { que non le dexe. } \\
& \text { Dezilde al cavallero } \\
& \text { cuerpo garrido } \\
& \text { que non se quexe } \\
& \text { en ascondido, } \\
& \text { que yo le doy mi fe } \\
& \text { que non le dexe. }
\end{aligned}
$$

Esta canción se incluyó, en 1556, en el cancionero llamado de Upsala con música a cinco voces de Nicolás Gombert, compositor flamenco que vivió varios años en España. Su melodía, sin duda tradicional, es la misma que sirvió de base a las famosas Diferencias de Cabezón. O sea, que el "canto del Caballero" es, ni más ni menos, el tema musical de "Dezilde al cavallero...", tema que inspiró también a otros dos compositores españoles de la época: Cristóbal de Morales y Diego Pisador ${ }^{6}$.

La identidad melódica de la pieza de Cabezón con la del Cancionero de Upsala había sido observada por más de un conocedor de la música española del Renacimiento. Existe un disco en que ambas aparecen deliberadamente juntas'.'En un importante artículo del Anuario $M u$ sical de Barcelona, José Romeu Figueras hizo notar ya en 1958 que el tema de Cabezón "es el mismo que el de la pieza de Gombert acogida

a Pedrell y a Bal). En 1944 publica S. Magariños el texto de Lope intitulándolo "Canción legendaria, con música de Antonio Cabezón" (Canciones populares de la Edad de Oro, Barcelona, 1944, p. 154). En la Antologia de la poesia española. Poesia de tipo tradicional, de D. Alonso y J. M. BlecuA (Madrid, 1956), se lee en la p. 240: "La canción del Caballero de Olmedo se halla entre las "diferencias" del maestro Cabezón". Etc., etc.

5 Cancionero de Upsala, ed. J. Bal y Gay, México, 1944, núm. 49. J. Romeu Figueras ha propuesto rebautizar este cancionero con el nombre de Cancionero Musical del Duque de Calabria (art. cit. infra, nota 8). El texto de "Dezilde al cavallero..." ha sido reproducido en varias antologias de la antigua lírica de tipo popular, desde la de Cejador hasta la de Alín, pasando por las de D. Alonso, Alonso-Blecua y Frenk Alatorre.

6 MoRAles († 1553) compuso una Misa "Dezilde al cavallero" (Opera omnia, t. 7, núm. XX; dato tomado de H. ANGlÉs, op. cit, infra, nota 9, p. I6); PIsADOR escribió una pieza para vihuela al tono de "Dezilde al cauallero" (no "Dejalde al caballero", como dicen Gallardo, Ensayo, t. 3, col. 1234, y Cotarelo), incluida en su Libro de musica de vihuela, Salamanca, 1552, libro I, fol. 4r-v. Curiosamente CotaRELo, loc. cit. supra, se imaginó que esta canción de Pisador era... la del Caballero de Olmedo.

7 Spanish Music of the Renaissance, New York ProMusica (Noah Greenberg, Musical Director), Decca, DL 9409 (comienzo de la cara 2). 
bajo el núm. 49 de nuestro Cancionero [de Upsala]"8; y al editar las Obras de música para tecla, arpa y vihuela (1578) de ANTONIO DE CABEZón en 1966, Mons. Higinio Anglés dice expresamente que la melodía de las Diferencias "no es la misma de "El cavallero de Olmedo", como venía diciéndose hasta aqui" 9 . En efecto, nada tiene que ver el "Que de noche le mataron..." con la pieza de Cabezón, si no es la casual mención de un caballero y una curiosa coincidencia métrica con "Dezilde al cavallero...", coincidencia que evidentemente propició la asociación. La musicología, que la inventó y la generalizó, se ha encargado de mostrar su falsedad.

Sólo falta ahora que la crítica literaria rectifique ese pequeño error. Sobre el cantar (y el baile) del Caballero de Olmedo no tenemos más testimonios que los que empiezan a proliferar desde comienzos del siglo xvir $^{10}$. Si existió antes -como es probable-, nada sabemos. Hemos perdido lo que parecía un valioso documento casi contemporáneo del origen de la leyenda. Y, cosa aún más triste, hemos perdido la melodía con la cual se cantaba "Que de noche le mataron / al caballero, / la gala de Medina, / la flor de Olmedo".

EI Colegio de México.

Margit Frenk Alatorre

\section{EL CALENDARIO DE ALFONSO REYES Y UNA NOTA SOBRE CARTONES DE MADRID}

Calendario es una colección de bocetos (de ensayos, cuentos, escenas...), que pertenece a lo que M. Olguín llama la segunda etapa de la obra de Alfonso Reyes ${ }^{1}$. La colección, publicada en 1924, fue organizada en octubre de $1923^{2}$. Estas fechas la colocan al final de la segunda etapa, que abarca los diez años (1914-1924), que Reyes pasó en España. Olguín clasifica Calendario como obra creativa, con lo cual

8 "Mateo Flecha el Viejo, la corte literariomusical del duque de Calabria y el Cancionero llamado de Upsala", $A n M, 13$ (1958), pp. 25-101; la cita, p. 92.-Nos preguntamos si al preparar la edición del Cancionero de Upsala don Jesús BAL. $\mathbf{Y}$ GAY no notó la concordancia entre la música de "Dezilde al cavallero..." y la de Cabezón, reproducida y comentada por él nueve años antes, Nada dice al respecto en la breve nota de la p. 70, que es donde hubiera podido deshacer la errónea asociación con el Caballero de Olmedo.

9 La edición, en 3 tomos, fue publicada por el Instituto Español de Musicología, Barcelona, 1966. Las "Diferencias sobre el Canto del Cavallero" figuran en el t. 3, núm. LXXIX; el comentario de Anglés, en la p. 15 de la introducción a ese tomo (sorprende un tanto lo de "no es la misma de «El cavallero de Olmedo»": como si se conociera la melodía de este cantar). Nótese que el texto dice sólo "canto", y no "canto llano" como puso Bal en sus Treinta canciones y como se ha venido citando después.

10 Cf., entre otros, F. Rico, Introducción a su citada ed., pp. 30-43, y José María ALín, El cancionero español de tipo tradicional, Madrid, 1968, pp. 739-740.

1 Manuel Olguín, Alfonso Reyes, ensayista, México, 1956, p. 11.

2 Alfonso Reyes, "Noticia de ediciones anteriores de Calendario", Obras completas, t. 2, México, 1956, p. 270. 